\title{
MOTIVATIONAL POWER OF GAMIFICATION: THE EFFECT OF PLAYFUL LEARNING ON PSYCHOLOGICAL NEEDS OF SELF-DETERMINATION THEORY
}

\author{
Bahar Kutun $^{1}$, Alke Martens ${ }^{2}$, \& Werner Schmidt ${ }^{1}$ \\ ${ }^{I}$ Business School, Technische Hochschule Ingolstadt (Germany) \\ ${ }^{2}$ Fakultät für Informatik und Elektrotechnik, Universität Rostock (Germany)
}

\begin{abstract}
Gamification, i.e. the integration of game design elements into a non-gaming environment, aims to increase users' engagement and motivation to achieve their goals regarding a given task. It is placed at the border between formal and informal learning approaches. Motivational difficulties are well known in educational settings, especially in Computer Science, where strict formal content meets very playful computer gamers. Hence, we followed the approach of gamification to raise the motivation of learners in the field of Business Process Management (BPM) lifecycle. We developed a board rallye game, based on 16 game design elements. The core of the rallye game is to convey knowledge in a playful way. In order to be able to determine the effects of the rallye game on several aspects, e.g. knowledge transfer and (learning) motivation, we carried out field experiments with 57 students at the Technische Hochschule Ingolstadt and at the Hochschule Augsburg. In this paper the perspective of self-determination theory (SDT), that has found general acceptance in motivational research, is used to understand and analyze the motivational power of gamification.
\end{abstract}

Keywords: Gamification, game based learning, business process management, self-determination theory, knowledge transfer.

\section{Introduction}

Regarding Computer Science education, same as education in related fields, e.g. Business Informatics, we always observe similar scenarios: almost all students love to play computer games, almost all students love the idea of smartness and of working on mobile devices, working in groups and being creative. At the same time, quite a lot of students have serious problems with acquiring formal knowledge. The rule of thumb says: the more formal (e.g. mathematically formal) a content is provided in a lecture, the less the students are motivated to take up the approach. A while ago we have made a test with a quite demanding (role playing) gaming environment, where the players have to learn lots of rules before being successful in the game. We let the students compare the rules of this game with rules in theoretical computer science and they admitted that the formal rules in theoretical computer science are less complicated than the rules in the game. We discussed this topic. In the result, our discussion ended with something even psychologists have a problem to put their finger on: motivation! Students described that in the game they are eager to learn, as the rules are kind of "standing in the way" of playing, and simply have to be learned to succeed in the game. In contrast to that, the building blocks of theoretical computer science contain no motivational factor, as the students' insight regarding the goal is missing. They have the short term goal to pass the exam, but they are not able to see the long term goal, i.e. deep understanding of their field of work.

Based on this observation and related to our knowledge in eLearning, game-based learning and learning design for a new world, we decided to make an approach where we develop a game, where part of the task is to understand BPM. BPM lifecycle includes activities that consider the design of business processes from analysis to execution and monitoring. Business process modeling is one of the activities in the lifecycle. Business process models are a comparably easy tool to describe processes and generally, students are not overwhelmed by its complexity. Nonetheless, we know that quite a lot of students are not very eager to grasp the rules, the underlying meaning and functionality of the BPM, and that they often have a kind of barrier, which they are not able to overcome. Thus, our approach is to use a rallye game as cover for the BPM lifecycle basics. As all of our students are eager to play on the computer, we designed a setting, where the game itself is not computer based. By using this design, we wanted to make clear that the game-based approach is helpful by itself - and not based on the innovation hype of a new computer game. Investigations like this have been carried out e.g. by the well-known beer game. As we wanted to 
put a finger on the motivational factor, which we heavily discussed with our students (who also are not sure what exactly motivation is), we put together the following research questions: without?

RQ1: Is the increase in knowledge higher when learning with gamification than when learning

RQ2: Is the (intrinsic) (learning) motivation higher when learning with gamification than when learning without?

Regarding the aspect of investigating motivation in a non-psychological study, we based our work on the SDT. In the following, we describe the game and afterward give an insight into our evaluation, which took place with more than 50 students. Finally, we draw conclusions and give ideas for further research in Section 4.

\section{Game design and implementation}

\subsection{Rallye track design}

In order to facilitate a flexible and modular layout of the rallye track, we developed single track sections per learning content portion, e.g., per BPM cycle activity. Thus, the rallye game ensures that the amount and order of learning units to be played can be determined by learners and teachers. There are two variants of the single track sections: a section with a given route to follow and a section with the opportunity to choose from alternative routes. A complete rallye track can be built up by linking the single track sections to each other (see Figure 1). Each single track section consists of fields with various meaning: 5 learning fields (blue), 3 question fields of various difficulty (green $=$ easy, yellow $=$ medium, red $=$ difficult), 2 event fields (star) and 1 empty field (white, only in single track section with alternative routes).

Figure 1. Example for a complete rallye track with 7 single track sections.

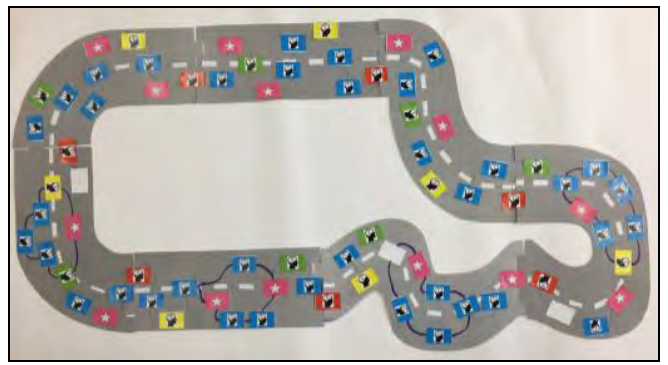

\subsection{Elements for knowledge transfer}

Since the BPM rallye aims to transfer knowledge in the field of the BPM lifecycle, elements for knowledge transfer are integrated into the game. For this purpose, we created 15 learning cards per BPM cycle activity. They include the learning content related to the BPM cycle activity and can be flexibly assigned to the single track sections. In order to check the learning content, we designed 18 control question cards per BPM cycle activity. On the front side are questions of various question types, e.g., open / closed questions or fill the gap questions. To give the players immediate feedback the answer of the question is printed on the back side of the control question card.

\subsection{Game design elements and SDT}

We have assigned the game mechanics (full list of game mechanics and their implementation in the game see Kutun \& Schmidt, 2018), to the SDT in order to identify their contribution to the satisfaction of the psychological needs (see Table 1).

Table 1. Matching game mechanics to the psychological needs.

\begin{tabular}{|l|l|}
\hline SDT & Game mechanics \\
\hline Need for autonomy & Customization \\
\hline Need for competence & $\begin{array}{l}\text { Badges, Clear goals, Competition, Countdown, Epic Meaning, } \\
\text { Feedback, Progression bars, Pyramid scoring, Quests, Ranking list, } \\
\text { Transparency of results }\end{array}$ \\
\hline Need for social relatedness & Epic meaning, Free lunch, Gifts \\
\hline
\end{tabular}

\subsection{Prototype and playing}

Based on the discussed game design we created a prototype. The components of the rallye game set are illustrated in Figure 2. 
Figure 2. Content of a rallye game box.

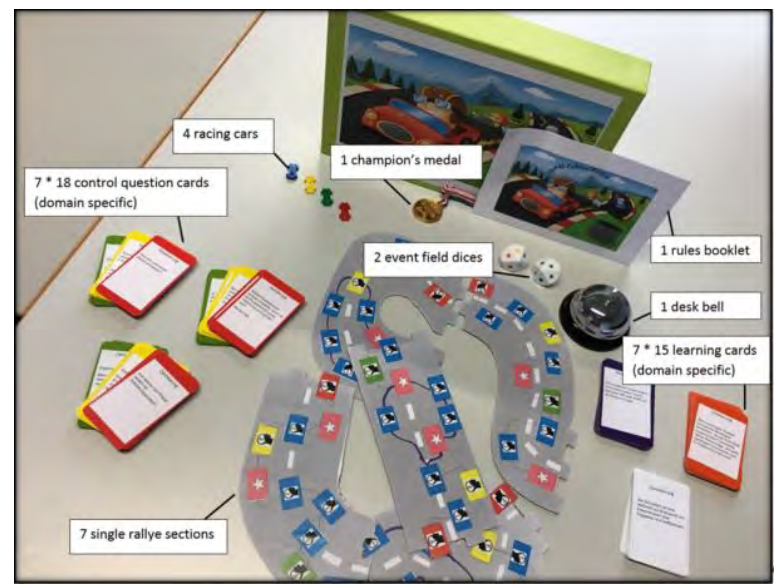

The players organize themselves in teams of 3 to 4 people. The teams create their own rallye track by determining the amount and order of learning content according to the teacher's instruction or to their own preferences. The youngest player begins playing. The game is played clockwise. The players move their racing cars field by field across the track and follow the instructions of the fields, e.g., drawing a learning or control question card. Learning content, control questions and their answers are read aloud, so that all team members can follow and discuss. If a racer reaches a question field, he may only proceed if he can answer the question correctly. The game ends when the first racer (winner) reaches the finish field.

\section{Evaluation and results}

After a successful technical test, in which the transparency of rules and rules booklet, as well as the playing time was checked, the game was tested and evaluated as part of a field experiment. We have determined the course of the field experiment as follows: first, the participating students were randomly divided into experimental and control group and in smaller teams of 3 to 4 within each group. To determine the current level of knowledge of the participants a knowledge test (pre) was carried out. The test included questions about the BPM lifecycle activities. All teams were asked to choose 3 BPM cycle activities and had a total of 60 minutes to play the rallye game or to study the lecture. Teams of the experimental group played the rallye game, while the teams of the control group were provided with a lecture script, which is usually used in the lecture to convey knowledge in the field of the BPM cycle. During this phase, a qualitative observation was made by the moderator / teacher. In order to analyze the increase in knowledge, we repeated the knowledge test as post-test after the field experiment. In a final step the students evaluated the field experiment. They assessed, whether the psychological needs of SDT could be met in the field experiment. Additionally, their statements with respect to flow experience or learning success were collected. The entire experiment took about 2 hours.

We carried out two field experiments in the described way. The first one took place in the course 'BPM' of the Bachelor's program 'Digital Business' at the Technische Hochschule Ingolstadt with 42 students. The second field experiment we conducted in the course 'BPM' of the Bachelor's program 'Business Informatics' at the Hochschule Augsburg with 15 students.

This paper presents the results of the knowledge tests (knowledge growth, see Figure 3 ) and the satisfaction of the psychological needs of SDT (see Figure 4).

Figure 3. Knowledge growth.

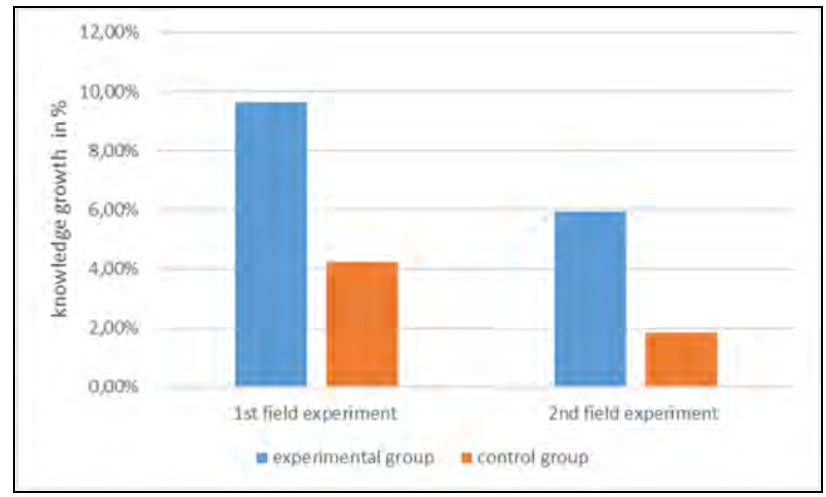


The knowledge growth is determined by comparing the pre and post knowledge tests. It is obvious that the experimental groups were able to achieve a higher increase in knowledge. Possibly this is due to the fact that the students in the experimental group have a higher (learning) motivation than the learners in the control group. This assumption will be investigated in more detail by analyzing the evaluation sheets.

With the rallye game an almost identical net effect could be measured in both field experiments. On average, the net effect of the rallye game was a $4.76 \%$ increase in knowledge. The time frame used for this was approximately 1 hour (= time to deal with the BPM cycle activities). This means learners could improve one grade within an hour. This grade level gain refers to a grading system with 10 levels from 1.0 (best) to 4.0 (= pass limit at 50\%). The results give some evidence for a positive answer to RQ1, i.e. that gamified learning can lead to a higher knowledge increase compared to traditional learning.

In order to analyze the satisfaction of the needs of SDT and thus to determine the (intrinsic) (learning) motivation, reliability analyses, significance tests and the measurement of the effect's strength were carried out. In addition, we conducted a single factor multivariate analysis of variance (MANOVA).

Figure 4 depicts the results of these validity checks for the first field experiment.

Figure 4. Satisfaction of psychological needs of SDT.

\begin{tabular}{|c|c|c|}
\hline & Dxperimental group & Control group \\
\hline \multicolumn{3}{|c|}{ Need for competence } \\
\hline $\mathrm{M}(\mathrm{SD})$ & 3,86 & 2,74 \\
\hline Chronbach's $\alpha$ & $\alpha=0,9 ;$ excellent reliability & \\
\hline F value & $F(1,40)=14,604$ & \\
\hline Significance level & $0,000<0,05$ & \\
\hline Effect strength & $\mathrm{d}=1,2 ;$ great effect & \\
\hline \multicolumn{3}{|c|}{ Need for social relatedness } \\
\hline $\mathrm{M}(\mathrm{SD})$ & 4,10 & 3,45 \\
\hline Chronbach's a & $\alpha=0,8 ;$ good reliability & \\
\hline F value & $\mathrm{F}(1,40)=5,784$ & \\
\hline Significance level & $0,011<0,05$ & \\
\hline Effect strength & $\mathrm{d}=0,8$; significant effect & \\
\hline \multicolumn{3}{|l|}{ Need for autonomy } \\
\hline $\mathrm{M}(\mathrm{SD})$ & 3,84 & 3,55 \\
\hline Chronbach's $\alpha$ & $\alpha=0,6 ;$ questionable reliability & \\
\hline F value & $F(1,40)=1,474$ & \\
\hline Significance level & $0,116>0,05$ & \\
\hline Effect strength & $\mathrm{d}=0,4$; small effect & \\
\hline
\end{tabular}

The significant effect on the basic psychological need for competence is reasonable, since the experimental group receives, for example, immediate feedback on answering control questions. Likewise, the feeling of social integration is higher in the experimental group due to the interaction with other players during the game round than in the control group. The fact that the control group can also meet the need for autonomy is probably due to the fact, that the students can make their own decisions regarding the reading sequence of the lecture notes for different BPM cycle activities.

For the 2nd field experiment, only evaluation sheets of the experimental group are available because the control group did not want to fill out the form. For this reason, the satisfaction of the psychological needs of SDT cannot be analyzed for the 2nd field experiment. However, the qualitative observation in both field experiments revealed a significantly higher level of commitment and fun in the experimental group.

According to the results of the analysis, the rallye game beneficially contributes to the satisfaction of the three basic psychological needs of SDT. Hence, RQ2, whether the (intrinsic) (learning) motivation is higher when learning with gamification than when learning without gamification, can also be answered positively. 


\section{Conclusion and future work}

We followed the gamification approach to develop a board game, which should support learning processes in the field of Business Process Management. We evaluated and tested the rallye game with two field experiments with university students. The experiences and feedback we collected indicate that the game is appropriate to transfer knowledge in a playful way. In addition, the results show that the rallye game can contribute to increase the (intrinsic) (learning) motivation of learners.

In order to extend empirical grounding the rallye game should be subject to further evaluation with several groups, e.g., employees in learning situations.

Based on the information on the evaluation sheets, it was also found that some students in the control group would rather participate in the experimental group and vice versa. For this reason, a field experiment can be carried out to analyze which effects occur when participants choose themselves the group in which they want to participate. Thus, the winner or loser problem can also be solved.

Based on the positive experience with the board game, it is interesting to find out whether the transfer of the concept to a digital version can also be successful. Therefore, there are plans to develop the rallye as a web-based game and analyze its effects on learning success and motivation.

Generally, we think that future learning will tend towards establishing more "fun" in the learning process. This can be reflected by a change in instructional methods, which might also contain the embedding of games or gamification aspects in the learning. Naturally, playful or game based learning takes place in children education, where it is a quite normal part of the instructional material. However, as soon as the child grows up, the perception is that learning, teaching and training have to be serious and no fun, to be accepted. Our impression is that a method mix is the most fruitful instructional design. Especially young students in their first years at the University are often missing the big picture. They know that they have to learn all the stuff provided by their teachers, but in quite a lot of cases, they don't understand why. As long as the big picture is missing, raising the motivation by e.g. choosing a game as one of multiple ways to mediate information can be fruitful, as our investigation shows. Regarding the idea of smart education, the integration of game, gamification, and serious learning seems to be the most promising - either in University as in school or high school setting.

\section{References}

Bartle, R. A.: Designing Virtual Worlds, Indianapolis: New Riders (2004).

Bartle, R. A.: Hearts, clubs, diamonds, spades: Players who suits MUDs, in: Journal of MUD research 1 (1), 19, pp. 1-28 (1996).

Björk, S., Holopainen, J.: Patterns in Game Design (Game Development Series), Rockland: Charles River Media (2004).

Deterding, S., Dixon, D., Khaled, R. and Nacke, L.: From game design elements to gamefulness: Defining gamification, MindTrek '11 Proceedings of the 15th International Academic MindTrek Conference: Envisioning Future Media Environments, pp. 9-15 (2011).

Deterding, S., Khaled, R. Nacke, L. and Dixon, D.: Gamification: Toward a definition, CHI 2011 Gamification Workshop Proceedings, pp. 12-15 (2011).

Hamari, J., Koivisto, J., Sarsa H.: Does gamification work? A literature review of empirical studies on gamification, Proceedings of the 47th Hawaii International Conference of System Sciences (HICCS); pp.3025-3034 (2014).

Kapp, K. M.: The Gamification of Learning and Instruction: Game-Based Methods and Strategies for Training and Education. San Francisco: Pfeiffer (2012).

Kutun, B. and Schmidt, W.: Rallye: Playful and Motivated Learning, EDULEARN18, pp. 735-741 (2018).

PRSH e.V.: http://www.prsh.de/2014/04/22/gamification-4-die-zielgruppe-als-spielgruppe/

Rosemann, H.: Arbeitshefte für Psychologie: Motivation: Motivationstheorien, Motivationsarten: Lern- und Leistungsmotivation, Aggression, Angst, Frustration, Konflikt und Widerspruch, Motivierung im Unterricht. Berlin: Polerz (1974).

Ryan, R. M., Deci, E. L.: Self-Determination-Theory: Basic Psychological Need in Motivation, Development and Wellness. New York: The Guilford (2017).

Schacht M, Schacht S.: Start the game: increasing user experience of enterprise systems following a gamification mechanism, in: Maedche A, Botzenhardt A, Neer L (Eds.) Software for people. Heidelberg: Springer, pp.181-199 (2012).

Schiefele, H.: Lernmotivation und Motivlernen. München: Franz Ehrenwirth, (1974).

Werbach, K., Hunter, D.: For the win: How Game Thinking can revolutionize your business, Philadelphia: Wharton Digital Press (2012). 